\title{
Emergency Department Length of Stay for Critically Ill Patients Followed Up in Red Zone
}

\author{
Fatih Cakmak ${ }^{1, \star}$, Ibrahim Ikizceli ${ }^{1}$, Derya Ozturk ${ }^{2}$, Ertugrul Altinbilek ${ }^{2}$, \\ Banu KarakusYilmaz ${ }^{2}$, Serap Biberoglu ${ }^{1}$, Ahmet Oluk ${ }^{3}$, Ahmet Cevdet Toksoz ${ }^{4}$
}

\author{
${ }^{1}$ Department of Emergency Medicine, \\ Cerrahpasa Faculty of Medicine, Istanbul \\ University Cerrahpasa, Istanbul, Turkey \\ ${ }^{2}$ Department of Emergency Medicine, \\ Sisli Hamidiye Etfal Training and \\ Research Hospital, Istanbul, Turkey \\ ${ }^{3}$ Department of Emergency Medicine, \\ Gaziosmanpasa Taksim Training and \\ Research Hospital, Istanbul, Turkey \\ ${ }^{4}$ Department of Emergency Medicine, \\ Balikesir State Hospital, Balikesir, Turkey

\section{*Correspondence} \\ fatih.cakmak@istanbul.edu.tr \\ (Fatih Cakmak)
}

\begin{abstract}
Objectives: The patients in red zone areas face acute or potentially life-threatening situations, complaints, vital disorders, diseases, or injuries that require emergent evaluation and treatment to prevent probable mortality and morbidity. We aimed to determine the variations in the lengths of stay of patients at the emergency department by examining different parameters and evaluate determinants that affect lengths of stay (in emergency room) of critically ill patients. Materials and Methods: All emergency department patients that were followed up in the red zone were included in this study. Patients' demographic data, major complaints on admission, vital findings, performed procedures and examinations, elapsed time for the diagnoses, patients' lengths of stay, and the causes of their prolonged waiting times were recorded and statistically analyzed. Results: The times elapsed for the diagnoses ranged between $6 \mathrm{~min}$ to $18 \mathrm{~h}$ in this study (mean: $1.62 \pm 1.79 \mathrm{~h}$ ). Patients' lengths of stay was between $6 \mathrm{~min}$ to $58 \mathrm{~h}$ (mean length of stay was $5.51 \pm 5.73 \mathrm{~h}$ ). The waiting time for cases that required consultation (7.17 h) was found to be statistically longer than those cases that required no consultations $(3.40 \mathrm{~h}$ ). Conclusion: To prevent delays in emergency room to inpatient unit transfers, hospital administrators should manage their bed capacities to a level that is compatible with the annual number of patient admissions. Increasing the number of geriatric wards may facilitate inpatient transfers of patients over 60 years age from emergency room and shorten the length of stay of that age group.
\end{abstract}

\section{Keywords}

Overcrowded, Emergency medicine, Waiting time, Red zone, Critically ill patients

\section{Introduction}

Emergency rooms (ER) are health units that provide uninterrupted service to patients requiring emergent treatment [1] and involve most public interaction. Therefore, the perception of the community towards the hospitals depends largely on the time spent in the ER and the services received [2]. Patients brought to the ER should be swiftly admitted to the appropriate clinics following their initial treatments and interventions so that the emergency service areas are vacated for other patients requiring immediate intervention. However, this is not always the case. Patients have to wait in the ER for long durations and are tardily transferred to the related clinics. This issue is observed not only in Turkey but also in most parts of the world [1]. Patients overcrowding the ER has become a serious public health problem [3].

Increased workload in the ER, long waiting hours, and subsequent overcrowding of patients often result in deterioration of the quality of care provided [4]. Patient overcrowding in ER may be due to the lack of adequate vacant beds in the hospital, increasing number of patients, inadequate number of emergency personnel, inadequately-sized ERs, late arrival of consultant physicians, delays in imaging and laboratory services, and increase in the number of patients with severe illnesses [5-7].

Waiting time for emergency services is the most important indicator of patient satisfaction in emergency care and is measured as a quality criterion in many organizations [8]. In this study, we aimed to measure the duration, variability, and reasons for long stays in the ER of a training and research hospital. We evaluated the variations in the length of stay of patients in the ER by studying different parameters and aimed to determine the factors affecting the length of stay of patients. Waiting time was assessed based on the presence of new admissions and awaiting examinations, consultation numbers and distributions and reasons for waiting according to admission complaints. We also sought solutions for emergency overcrowding and to reduce the waiting times of patients in ER. 
TA B L E 1. The distributions of defining characteristics and waiting times.

\begin{tabular}{|c|c|c|c|}
\hline$(n=596)$ & $\mathbf{N}$ & $\%$ & ER waiting time \\
\hline \multicolumn{4}{|l|}{ Age } \\
\hline between $0-18$ & 23 & 3.9 & $5.33 \pm 8.48$ \\
\hline between $19-40$ & 112 & 18.8 & $4.02 \pm 3.51$ \\
\hline between $41-60$ & 149 & 25.0 & $5.21 \pm 6.05$ \\
\hline between $61-80$ & 222 & 37.2 & $6.15 \pm 6.40$ \\
\hline 81 and above & 90 & 15.1 & $5.99 \pm 4.43$ \\
\hline $\mathrm{p}$ & 0.001 & & \\
\hline \multicolumn{4}{|l|}{ Gender } \\
\hline Female & 242 & 40.6 & $5.65 \pm 5.16$ \\
\hline Male & 354 & 59.4 & $5.32 \pm 6.06$ \\
\hline $\mathrm{p}$ & 0.100 & & \\
\hline \multicolumn{4}{|l|}{ Day of Admission } \\
\hline Weekday & 476 & 79.9 & $5.26 \pm 5.07$ \\
\hline Weekend & 120 & 20.1 & $6.22 \pm 7.74$ \\
\hline $\mathrm{p}$ & 0.755 & & \\
\hline \multicolumn{4}{|l|}{ Time of admission } \\
\hline Between 8 a.m. - 12 p.m. & 119 & 20.0 & $6.46 \pm 8.58$ \\
\hline Between 12 p.m. - 4 p.m. & 104 & 17.4 & $4.54 \pm 4.20$ \\
\hline Between 4 p.m. - 8 p.m. & 117 & 19.6 & $6.15 \pm 6.63$ \\
\hline Between 8 p.m. - 12 a.m. & 126 & 21.1 & $5.42 \pm 4.14$ \\
\hline Between 12 a.m. - 4 a.m. & 83 & 13.9 & $4.63 \pm 3.26$ \\
\hline Between 4 a.m. - 8 a.m. & 47 & 7.9 & $4.66 \pm 2.88$ \\
\hline $\mathrm{p}$ & 0.394 & & \\
\hline \multicolumn{4}{|l|}{ Manner of admission } \\
\hline Through their own means & 63 & 10.6 & $4.39 \pm 3.19$ \\
\hline Through Emergency Medical Service "112" & 369 & 61.9 & $5.63 \pm 5.90$ \\
\hline From epicenters & 7 & 1.2 & $3.60 \pm 2.87$ \\
\hline Yellow Zone & 148 & 24.8 & $5.66 \pm 6.26$ \\
\hline Green zone & 9 & 1.5 & $3.67 \pm 2.06$ \\
\hline $\mathrm{p}$ & 0.627 & & \\
\hline
\end{tabular}

\section{Materials and methods}

This prospective study was conducted at the Emergency Department of a training and research hospital in Turkey. The study was approved by the Sisli Hamidiye Etfal Training and Research Hospital Ethics Committee (approval date: 25.06.2013 number: 418). All patients gave written informed consent before their enrollment in the study.

Patients who were admitted to the ER red zone in July 2013 were included in the study. Monthly patient admission to the ER was 36,320 at the time of the study.

According to the Turkish health system, the ER has three levels of emergency triage scale (coded in red, yellow and green colors in order of decreasing acuity). The red triage code indicates life threatening, rapid aggressive approach, and situations requiring urgent simultaneous evaluation and treatment. In such cases, a patient is immediately transferred to the red zone. This zone also includes situations that need evaluation and treatment within $10 \mathrm{~min}$. Moreover, all patients transferred to the hospital in an ambulance are also categorized as red-zone patients.

For each patient, the time of arrival, age, manner of admission, gender, vital findings, complaints at the time of admission, medical history, further examinations, medical applications, diagnosis and the duration of diagnosis, duration of waiting in the red-zone, requested consultations, reasons for waiting, and results were recorded in a survey data form. Waiting time was defined as the period from the end of the patient's diagnostic procedures to discharge or hospitalization. The duration for diagnosis indicated the time from hospital admission to the end of diagnostic procedures. 
TA B L E 2. Waiting Time Evaluation Regarding Presence of further examinations and applications.

\begin{tabular}{|lcccc|} 
(n=596) & n & \% & \multicolumn{2}{c|}{ Waiting time (h) } \\
Further examinations & & & Min - Max & Mean \pm SD \\
Computed Tomography & 272 & 45.6 & $0.1-58.0$ & $6.22 \pm 6.75$ \\
\hline Ultrasonography & 87 & 14.6 & $0.2-42.0$ & $6.66 \pm 6.10$ \\
\hline Magnetic Resonance Imaging & 40 & 6.7 & $0.5-15.5$ & $6.32 \pm 3.96$ \\
\hline CT Angiography & 28 & 4.7 & $1.0-58.0$ & $9.01 \pm 10.84$ \\
\hline Doppler USG & 15 & 2.5 & $0.75-20.0$ & $7.49 \pm 5.94$ \\
\hline Endoscopy & 14 & 2.4 & $2.0-26.4$ & $12.05 \pm 8.29$ \\
\hline Echocardiography & 6 & 1.0 & $3.8-11.5$ & $6.30 \pm 2.94$ \\
\hline Electroencephalography & 3 & 0.5 & $13.0-23.0$ & $18.0 \pm 7.07$ \\
\hline Applications & & & & \\
Intubation & 32 & 5.4 & $0.5-17.8$ & $3.84 \pm 3.88$ \\
\hline CPR & 6 & 1.0 & $0.75-3.5$ & $1.97 \pm 1.18$ \\
\hline Hemodialysis & 4 & 0.7 & $1.5-56.0$ & $19.12 \pm 24.87$ \\
\hline Tube Thoracostomy & 2 & 0.3 & $4.5-16.0$ & $10.25 \pm 8.13$ \\
\hline Central Vein Catheterization & 2 & 0.3 & $4.1-8.0$ & $6.05 \pm 2.75$ \\
\hline Other & 8 & 1.4 & $2.5-16.75$ & $7.42 \pm 5.12$ \\
\hline
\end{tabular}

\section{Statistical analysis}

The Number Cruncher Statistical System (NCSS, 2007), PASS Power Analysis and Sample Size (PASS, 2008) Statistical Software (Utah, USA) were used for statistical analyses. The descriptive statistics of the variables were indicated using mean, standard deviation, median, frequency, and ratio. In addition, the Mann-Whitney U test was employed to compare the parameters between groups with abnormal distribution. The results were evaluated in a confidence interval of $95 \%$ and by the significance level of $\mathrm{p}<0.05$ (CI: 95\%, $\mathrm{p}<0.05$ ).

\section{Results}

A total of 596 patients who were followed up in the red zone of the ER were included in the study. The distributions of defining characteristics of patients are shown in Table 1. It was observed that ER waiting times for patients in age groups 4 and 5 were significantly higher than in the age group $2(\mathrm{p}<$ $0.01)$.

Waiting times regarding the presence of new admissions and examinations are demonstrated Table 2.

The number of consultations ranged from one to five, with an average of $1.51 \pm 0.78$. The waiting times for patient who received consultations are shown in Table 3. It was observed that ER waiting times for patients who received consultations were significantly higher than those who did not receive any consultations $(\mathrm{p}<0.01)$.

The duration for diagnosis ranged between $6 \mathrm{~min}$ to $18 \mathrm{~h}$, with a mean average of $1.62 \pm 1.79 \mathrm{~h}$. The most common diagnoses in the included patients are as follows: pneumonia 14.77\% ( $\mathrm{n}=88)$, non-STEMI 7.38\% $(\mathrm{n}=44)$, non-specific chest pain $5.54 \%(\mathrm{n}=33)$, cerebrovascular accident $(\mathrm{CVA})$ $4.87 \%(n=29)$, epileptic seizure $3.69 \%(n=22)$, congestive heart failure $3.36 \%(\mathrm{n}=20)$, STEMI $3.02 \%(\mathrm{n}=18)$, and chronic obstructive pulmonary disease $3.02 \%(n=18)$. The overall average waiting time for patients was $5.51 \pm 5.73 \mathrm{~h}$ (range $6 \mathrm{~min}$ to $58 \mathrm{~h}$ ). The percentage of patients who waited for the consulting physician was $40.3 \%(\mathrm{n}=240)$, and the average waiting time for consulting physician was $7.85 \pm 7.59$ $\mathrm{h}(6 \mathrm{~min}$ to $58 \mathrm{~h})$.

Distribution of waiting times and reasons are shown in Table 4 , and the distributions of completion are given in Table 5.

\section{Discussion}

Overcrowding in ER results due to increased waiting time, increased number of patients that left without being seen, and decreased patient satisfaction [9, 10]. Kilicaslan et al. observed that $7 \mathrm{pm}$ to $11 \mathrm{pm}$ was the most crowded time of admission [11]. According to another study, 28\% of ER managers reported that $3 \mathrm{pm}$ to $11 \mathrm{pm}$ saw the most overcrowding in the ER. The National Hospital Ambulatory Medical Care Survey (NHAMCS) data reported the most crowded times for ER clinics in the US were 10:00 - 12:00 $\mathrm{h}$ and 16:00 - 20:00 $\mathrm{h}$ [12]. Our findings are consistent with the findings reported by NHAMCS.

Singal et al. emphasized that geriatric patients had more co-morbidities compared to younger patients, and therefore, they stayed comparatively longer in the ER. In addition, these patients had higher rates of hospitalization and urgency also $[13,14]$. Bozkurt et al. documented that the older population's admittance rate to the ER was higher [15]. In our study, it was observed that geriatric patients were more frequently admitted to the ER with a red triage code.

No significant gender difference regarding urgency was observed in studies conducted in the US [16, 17]. The gender difference regarding urgency between our study and that in the US study could be attributed to the reluctance of female patients to visit the ER alone. Furthermore, men may be 
TA B L E 3. Consultation Numbers and Distributions. Waiting Time Evaluation Regarding Presence of Consultation.

\begin{tabular}{|c|c|c|c|}
\hline$(n=596)$ & Min - Max & Mean & SD \\
\hline \multirow[t]{2}{*}{ Number of consultations } & 1.00 to 5.00 & 1.51 & 0.78 \\
\hline & n $(\%)$ & \multicolumn{2}{|c|}{ Waiting time (h) } \\
\hline Requested consultations & & Min - Max & Mean $\pm \mathbf{S D}$ \\
\hline Internal medicine & $100(16.8 \%)$ & 0.1 to 56 & $9.82 \pm 8.25$ \\
\hline Neurology & $71(11.9 \%)$ & 0.75 to 23 & $6.43 \pm 4.18$ \\
\hline Infectious diseases & $46(7.7 \%)$ & 1.15 to 58.0 & $9.45 \pm 10.91$ \\
\hline Orthopedics & $37(6.2 \%)$ & $0.5-42.0$ & $5.66 \pm 7.18$ \\
\hline Cardiology & $27(4.5 \%)$ & 1.0 to 22.0 & $5.66 \pm 4.01$ \\
\hline General Surgery & $25(4.2 \%)$ & 0.2 to 42.0 & $5.73 \pm 4.78$ \\
\hline Nephrology & $14(2.3 \%)$ & 2.0 to 56.0 & $9.66 \pm 3.02$ \\
\hline ENT & $13(2.2 \%)$ & $0.2-18.0$ & $2.84 \pm 1.06$ \\
\hline Plastic surgery & $11(1.8 \%)$ & $0.25-14.0$ & $6.61 \pm 4.79$ \\
\hline Gastroenterology & $7(1.2 \%)$ & 2.0 to 10.3 & $6.26 \pm 3.30$ \\
\hline Thoracic Surgery & $7(1.2 \%)$ & 2.5 to 16 & $7.00 \pm 6.09$ \\
\hline Urology & $7(1.2 \%)$ & 1.5 to 58 & $24.50 \pm 29.09$ \\
\hline Cardiovascular Surgery & $6(1.0 \%)$ & $4.5-16.0$ & $10.25 \pm 8.13$ \\
\hline Gynecology & $2(0.3 \%)$ & $0.5-3.5$ & $2.00 \pm 2.12$ \\
\hline Other & $130(21.8 \%)$ & 0.5 to 58 & $4.61 \pm 3.21$ \\
\hline \multirow[t]{2}{*}{ Waiting Time Evaluation Regarding Presence of Consultation } & \multicolumn{2}{|c|}{ Waiting Time } & $\mathrm{p}$ \\
\hline & Min - Max (median) & Mean $\pm \mathrm{SD}$ & \\
\hline No Consultation $(\mathrm{n}=262)$ & $0.10-26.00(2.50)$ & $3.40 \pm 2.91$ & $0.001 * *$ \\
\hline Consultation Requested $(\mathrm{n}=334)$ & $0.10-58.00(6.00)$ & $7.17 \pm 6.77$ & \\
\hline
\end{tabular}

Mann-Whitney U Test **p<0.01.

admitted to medical institutions more because of their active involvement in work life. About $50.5 \%$ of patients are discharged from the red zone without hospitalization. This high rate is probably because there is no short stay or observation unit for patients who need to be monitored. The overall followup of critically-ill patients was done in red zone of the hospital.

The radiology, laboratory, and other associated departments provided delayed services as a result of high workload, thus, increasing the waiting times of patients [6, 18, 19]. In our study, the waiting times for patients who received CT, USG, MRI, and EEG examinations were found to be higher. The inpatients were scheduled to receive an USG examination only after consulting with a radiology assistant. Since the radiology department serves both hospitalized patients and walk-in cases, the emergency patients are further delayed when they need USG examinations. This issue can be resolved by assigning a radiology specialist and a USG device specifically for the ER department.

In our hospital, MRIs are performed based on an appointment system. This causes further delay in providing timely treatment to patients. The hospital does not provide endoscopy examinations after work hours; therefore, patients may have to wait for $12 \mathrm{~h}$ for the next working day for the re-opening of endoscopy labs. Similarly, the hospital does not provide EEG services after work hours; therefore, the patients have to wait for an average of $18 \mathrm{~h}$ to receive EEG examination.
Espinosa et al. [20] noticed no significant difference between the number of patients waiting in the ER for an emergency situation and the number of patients that had come to the ER for other hospital-related reasons when the ER is crowded.

The average duration of stay in the ER was indicated to be $143.07 \mathrm{~min}$ by Aydın et al. [21], $120 \mathrm{~min}$ by Kilicaslan et al. [11], and 210 min by Oktay et al. [13] According to the CDC data of 2005, the average duration of stay was $210 \mathrm{~min}$ in the ER in the US [22]. Henneman et al. documented that the average duration of stay in the ER was 328 min for hospitalized patients and $176 \mathrm{~min}$ for discharged patients [23]. Our findings are consistent with the findings by Henneman et al. due to the hospitalization of the majority of the patients that are admitted to the red zone.

Insufficient numbers of consultant doctors and transportation difficulties are other reasons for overcrowding in ER [6]. A study conducted by Curry and Wang found that the consultation rate was $28.1 \%$ in the hours when the ER is crowded and $21.4 \%$ in the hours when there are a few number of patients [24]. We also found similar consultation rates in our study. The duration of stay in the ER was longer for patients who received consultation than for patients who received no consultation in the ERs.

Derlet et al. reported that most of the patients who required hospitalization were treated in the ER, leading to an increase in the waiting time in the ER $[6,19]$. In our study, the waiting 
TA B L E 4. Distribution of Waiting Times and Reasons.

\begin{tabular}{lccc} 
Reasons for the patient's waiting* & n (\%) 596 & \multicolumn{2}{c}{ Waiting Time (h) } \\
& & Min - Max & Mean \pm SD \\
\hline Waiting for Consultant Physician & $240(40.3 \%)$ & 0.1 to 58.0 & $7.85 \pm 7.59$ \\
\hline Patient Monitored in the ER without being transferred to another clinic & $196(32.9 \%)$ & 0.1 to 13.0 & $3.68 \pm 2.71$ \\
\hline Patient waiting for the results of further examinations & $144(24.2 \%)$ & 0.5 to 58 & $7.76 \pm 7.23$ \\
\hline Awaiting reply for transfer to external center & $143(24.0 \%)$ & 0.3 to 18.5 & $4.32 \pm 3.81$ \\
Patients that were monitored in the ER, without expected hospitalization & $116(19.5 \%)$ & 0.5 to 58 & $8.03 \pm 7.47$ \\
\hline No vacancy in the ICU & $76(12.8 \%)$ & 0.8 to 18.5 & $5.50 \pm 4.37$ \\
\hline No related clinic & $66(11.1 \%)$ & 0.3 to 16.0 & $3.26 \pm 3.01$ \\
\hline No vacancy in the related clinic & $49(8.2 \%)$ & $0.5-42.0$ & $10.02 \pm 7.57$ \\
The operation room and/or team is occupied & $9(1.5 \%)$ & 1.5 to 13.25 & $4.91 \pm 4.47$ \\
Waiting Time $(\mathbf{h})$ (for all cases) & & 0.1 to 58 & $5.51 \pm 5.73$
\end{tabular}

*There is more than one reason for waiting.

TA B L E 5. The Distribution of Completion.

\begin{tabular}{|lccccc|}
\hline & N & \%96) & \multicolumn{2}{c}{ Waiting Time (h) } \\
\hline Form of Completion & & & Min - Max & Mean \pm SD \\
\hline Patient has been discharged from the ER. & 301 & 50.5 & 0.1 to 58.0 & $5.54 \pm 5.50$ \\
\hline Transferred to external services & 144 & 24.2 & 0.3 to 18.5 & $4.37 \pm 3.87$ \\
\hline Transferred to clinics & 90 & 15.1 & $0.5-42.0$ & $7.71 \pm 6.56$ \\
\hline Voluntarily discharged from the hospital & 27 & 4.5 & 0.1 to 8.0 & $2.86 \pm 2.08$ \\
\hline Received an operation & 12 & 2.0 & 0.2 to 56.0 & $9.20 \pm 16.38$ \\
\hline Admitted to coronary ICU & 11 & 1.8 & $0.5-9.0$ & $4.79 \pm 3.16$ \\
\hline Admitted to the general ICU & 5 & 0.8 & $1.0-17.8$ & $5.68 \pm 6.92$ \\
\hline Exitus & 3 & 0.5 & 0.75 to 3.0 & $2.08 \pm 1.18$ \\
\hline Left the ER without permission & 3 & 0.5 & 0.3 to 12.75 & $4.77 \pm 6.93$ \\
\hline
\end{tabular}

times for patients, monitored in the ER and then discharged without consultation, were found to be lower than the patients waiting for consultation. The tardiness of the consultant doctors, examination of patients in the ER without transferring them to the appropriate clinics, and treating patients in the ER instead of hospitalization may lead to overcrowding in the ER and prolonged ER stays. It is suggested that further examinations and studies should be done after the patients are transferred to the clinics.

In the US, the average waiting time before admission to the ICU is $3 \mathrm{~h}$; however, this time can go up to $5.8 \mathrm{~h}$ in overcrowded ER $[25,26]$. We observed that our findings are in agreement with those in the available literature.

According to the report published by Australasian College for Emergency Medicine in 2004, 1509 patients were being treated in the ER and that 704 of these patients awaited hospitalization. It reported that $83.5 \%$ of patients who were expected to be hospitalized remained in the ER for more than $8 \mathrm{~h}$, occupying $39 \%$ of the beds in the ER. The same study indicated that $51.6 \%$ of ER patients waited on stretchers instead of being on beds due to non-availability of vacant spaces [27]. In a study on the American College of Emergency Physicians, $62 \%$ of doctors reported that one-fifth of the ER patients were awaiting hospitalization at any time of the day, and $64 \%$ doctors said that these patients waited on an average of 4 to $12 \mathrm{~h}$ or longer in the ER for hospitalization [28]. Our findings are also similar to above previous findings. The waiting time of patients awaiting an opening of the concerned clinic was found to be significantly higher compared to the waiting time of patients awaiting an external transfer. The patients were transferred to external centers due to the lack of a relevant clinic in the hospital, and the absence of a vacancy in the ICU or in the relevant clinic.

Insufficient number of beds or ineffective use of the existing capacity is not a problem related to the ER, but is instead related to hospital management and the healthcare system. The healthy operation of emergency services can only be possible with correct allotment /designation of beds in the clinics, ICU, and the ER, and by keeping the occupancies of available beds at an optimal level. Several factors can facilitate the operations in the emergency services: an adequate number of staff, up-todate and faster equipment, planning the schedule according to busy hours, and the assignment of qualified medical staff in the ER [29]. 


\section{Conclusion}

In order to reduce undue delays, hospital management should increase the bed capacity of the hospital. In addition, the hospital management should take immediate remedial measures to accelerate the consultation system and hospitalization of patients. To reduce the time spent in waiting for the results of further examinations in the ER, short stay or observation units should be established in the ER. After the diagnostic process is completed, patients must be followed-up in such units. This is because reducing waiting time due to delays in further examinations or consultations improves patient experience and hospital quality. Moreover, each additional hour spent in the ER increases healthcare expenditures. Consequently, reducing the medically-unnecessary length of stay in the ER should be a goal of hospital administrations.

\section{ACKNOWLEDGEMENTS}

I would like to express my gratitude to all those who helped me during the writing of this manuscript. Thanks to all the peer reviewers and editors for their opinions and suggestions.

\section{CONFLICT OF INTEREST}

The authors have no conflicts of interests to declare.

\section{REFERENCES}

[1] Weiss SJ, Derlet R, Arndahl J, et al. Estimating the Degree of Emergency Department Overcrowding in Academic Medical Centers: Results of the National Emergency Department Overcrowding Study (NEDOCS). Acad Emerg Med. 2004;11:38-50.

[2] Zeytin AT, Cevik AA, Acar N, et al. Characteristics of Patients Presenting to the Academic Emergency Department in Central Anatolia. Turk J Emerg Med. 2016;14:75-81.

[3] Cha WC, Ahn KO, Shin SD, et al. Emergency Department Crowding Disparity: a Nationwide Cross-Sectional Study. J Korean Med Sci. 2016;31:1331-1336.

[4] Brouns SHA, van der Schuit $\mathrm{KCH}$, Stassen PM, et al. Applicability of the modified Emergency Department Work Index (mEDWIN) at a Dutch emergency department. PLOS ONE. 2017;12:e0173387.

[5] Derlet RW, Richards JR. Emergency Department Overcrowding in Florida, New York, and Texas. South Med J. 2002; 95:846-849.

[6] Derlet RW, Richards JR. Overcrowding in the Nation's Emergency Departments: Complex Causes and Disturbing Effects. Ann Emerg Med. 2000;35:63-67.

[7] Yarmohammadian MH, Rezaei F, Haghshenas A, et al. Overcrowding in emergency departments: A review of strategies to decrease future challenges. J Res Med Sci. 2017;22:23.

[8] Gardner RL, Sarkar U, Maselli JH, et al. Factors associated with longer ED lengths of stay. Am J Emerg Med. 2007;25:643-650.

[9] Moskop JC, Sklar DP, Geiderman JM, et al. Emergency department crowding, part 1-concept, causes, and moral consequences. Ann Emerg Med. 2009;53:605-611.

[10] Han JH, France DJ, Levin SR, et al. The effect of physician triage on emergency department length of stay. J Emerg Med. 2010;39:227-233.
[11] Kilicaslan I, Bozan H, Oktay C, et al. Demographic properties of patients presenting to the emergency department in Turkey. Turk J Emerg Med. 2005;5:5-13.

[12] McCaig LF, Burt CW. National hospital ambulatory medical care survey: 2002 emergency department summary. Adv Data. 2004;18:1-34.

[13] Oktay C, Cete Y, Eray O, et al. Appropriateness of emergency department visits in a Turkish University Hospital. Croat Med J.2003;44:585-591.

[14] Singal BM, Hedges JR, Rousseau EW, et al. Geriatric patient emergency visits part I: Comparison of visits by geriatric and younger patients. Ann Emerg Med.1992;21:802-807.

[15] Bozkurt S, Atilla R, Türkçüer İ, et al. Differences in management between young and elderly patients in the emergency department. Turk J Emerg Med. 2006;6:16-24.

[16] Horwitz LI, Green J, Bradley EH. US emergency department performance on wait time and length of visit. Ann Emerg Med. 2010;55:133-141.

[17] Young GP, Wagner MB, Kellermann AL, et al. Ambulatory visits to hospital emergency departments. Patterns and reasons for use. 24 Hours in the ED Study Group. JAMA.1996;276:460-465.

[18] Richards JR, Navarro ML, Derlet RW. Survey of directors of emergency departments in California on overcrowding. West J Med. 2000;172:385388.

[19] Derlet RW. Overcrowding in emergency departments: Teaching, nonteaching hospitals, and state government. Ann Emerg Med. 2000;35:6368.

[20] Espinosa G, Miro O, Sanchez M, et al. Effect of external and internal factors on emergency department overcrowding. Ann Emerg Med. 2002;39:693-695.

[21] Tayfun Aydın, ŞuleAkköse Aydın, ÖzlemKöksal, et al. Evaluation of Features of Patients Attending the Emergency Department of Uludag University Medicine Faculty Hospital and Emergency Department Practices. Eurasian J Emerg Med. 2010;9:163-168.

[22] Nawar EW, Niska RW, Xu J. National hospital ambulatory medical care survey: 2005 emergency department summary. Adv Data. 2007;29:1-32.

[23] Henneman PL, Nathanson BH, Li H, et al. Emergency department patient swho stay more than 6 hour scontribute to crowding. J EmergMed. 2010;39:105-112.

[24] Cury DG, Wang DM. Variation of consultations practice in urban emergency medicine physicians. Can J Emerg Med. 2006;8:182-183.

[25] Trzeciak S, Rivers EP. Emergency department overcrowding in the United States: an emerging threat to patient safety and public health. Emerg Med J. 2003;20:402-405.

[26] Cowan RM, Trzeciak S. Clinical review: Emergency department overcrowding and the potential impact on the critically ill. Critical Care. 2005;9:291-295.

[27] Roberto Forero, Sally McCarthy, Ken Hillman. Access block and emergency department overcrowding. Critical Care. 2011;15:216.

[28] ACEP Crowding Resources Task Force Responding to Emergency Department Crowding: A Guidebook for Chapters. American College of Emergency Physicians. 2003:19.

[29] Ersel M, Karcioglu O, Yanturali S, et al. Emergency Department utilization characteristics and evaluation for patient visit appropriateness from the patients' and physicians' point of view. Turk J Emerg Med. 2006;6:25-35.

How to cite this article: Fatih Cakmak, Ibrahim Ikizceli, Derya Ozturk, Ertugrul Altinbilek, Banu KarakusYilmaz, Serap Biberoglu, et al. Emergency Department Length of Stay for Critically Ill Patients Followed Up in Red Zone. Signa Vitae. 2021;17(1):63-68. doi:10.22514/sv.2020.16.0048. 